\title{
Phyllanthus niruri and Chrysanthellum americanum in association with potassium and magnesium citrates are able to prevent symptomatic episode in patients affected by recurrent urinary stones: A prospective study
}

\author{
Tommaso Cai ${ }^{1}$, Daniele Tiscione ${ }^{1}$, Marco Puglisi ${ }^{1}$, Gianni Malossini ${ }^{1}$, Lorenzo Ruggera ${ }^{2}$, \\ Paolo Verze ${ }^{3}$, Davide Arcaniolo ${ }^{4}$, Alessandro Palmieri ${ }^{5}$ \\ ${ }^{1}$ Department of Urology, Santa Chiara Regional Hospital, Trento, Italy; \\ 2 Department of Urology, University of Padua, Padua, Italy; \\ ${ }^{3}$ Department of Medicine, Surgery, Dentistry "Scuola Medica Salernitana" - University of Salerno, Baronissi, Italy; \\ ${ }^{4}$ Department of Urology, University Vanvitelli, Naples, Italy \\ ${ }^{5}$ Department of Urology, University of Naples, Federico II, Naples, Italy.
}

\begin{abstract}
Summary Objective: The aim of this study is to evaluate the efficacy of a food supplement containing Phyllanthus niruri and Chrysanthellum americanum in association with potassium and magnesium citrates in the treatment and prophylaxis of urinary stones.

Materials and methods: Eighty-two patients (mean age $49.7 \pm$ 11.2) with history of urinary stones received this food supplement, one capsule a day for 6 months. Each administration contained a combination of the following ingredients: $244 \mathrm{mg}$ Potassium citrate, $735 \mathrm{mg}$ Magnesium citrate, Phyllanthus (Phyllantus niruri) herb d.e. 15\% mg Tannins $220 \mathrm{mg}$, Chrysanthellum (Chrysanthellum americanum Vatke) plant d.e. 1/4 $55 \mathrm{mg}$. After 6 months, all patients underwent urologic visit, urinalysis, imaging and quality of life $(2 o L)$ questionnaires evaluation. Each patient was also evaluated by computed tomography (CT) scan at baseline and at 6 months.
\end{abstract}

Result: From January 2018 to March 2019, 82 patients (mean age $49.7 \pm 11.2$ ) completed the follow-up period and were analyzed. Fifty patients showed lower stone dimensions (60.9\%). The average stone size was $0.9 \mathrm{~mm}$, with a significant reduction in comparison with the baseline $(-6.7 \mathrm{~mm} \pm 3 \mathrm{~mm})(p<0.001)$. Forty-nine patients $(59.7 \%)$ did not show any symptomatic episode with an improving in $20 L(+0.4 \pm 0.1)(p<0.001)$ in comparison with the baseline. At the end of the follow-up period, 27 patients out of 82 were stone-free (32.9\%). Moreover, we report a significant reduction of patients with asymptomatic bacteriuria (ABU) between the baseline and the end of the follow-up evaluation $(p<0.001)$.

Conclusions: In conclusion, this food supplement is able to improve quality of life in patients with urinary stones, reducing symptomatic episodes and the prevalence of $A B U$.

KEY WORDS: Stones; Phyllanthus niruri; Chrysanthellum americanum; Potassium; Magnesium; Asymptomatic bacteriuria.

Submitted 16 April 2021; Accepted 26 April 2021

\section{INTRODUCTION}

Urinary tract stones are one of the most common cause of urological visits, with a prevalence among urological patients of $1-15 \%(1,2)$. The impact on everyday clini- cal practice is high, due to the high number of recurrences and due to the impact of symptoms on patients' quality of life $(2,3)$.

The recurrence rate of urinary calculi is $50 \%$ within 10 years of the first episode $(3,4)$. Symptomatic recurrence episodes are associated with high direct and indirect costs (admission to emergency departments, imaging, drugs and working day lost). For these reasons, the prevention of symptomatic episodes due to urinary stones should be the first aim in the management of this kind of patients. Several authors recommended some diet interventions for reducing the risk of urinary stone formation and its recurrence but there is no conclusive consensus in the literature regarding the effectiveness of dietary interventions and recommendations about specific diets for patients with urinary calculi (5). On the other hand, the use of medicinal plants and nutraceuticals have long been used worldwide for the management of recurrence in patients affected by urinary stones (6). Ettinger et al., published in 1997 one of the first clinical trial on the use of potassium-magnesium citrate in preventing recurrent calcium oxalate kidney calculi, demonstrating that potassium-magnesium citrate effectively prevents recurrent calcium oxalate stones (7). Focusing on the plant extracts, Phyllanthus niruri, commonly known as "stone-breaker", is able to increases urinary excretion of magnesium and potassium and to cause a significant decrease in urinary oxalate and uric acid in patients with hyperoxaluria and hyperuricosuria, contributing to the elimination of urinary calculi (4). Moreover, Chrysanthellum americanum seems to be effective in the reduction of stone formation, probably due to the effect of chrysantellin, a saponin, on the stone aggregation (8).

Starting from these evidences, we aim to evaluate the efficacy of a medical device containing Phyllanthus niruri and Chrysanthellum americanum in association with potassium and magnesium citrates in the treatment and prophylaxis of symptomatic episode in patients affected by recurrent uncomplicated urinary stones. 


\section{MATERIALS AND METHODS}

\section{Study schedule and population}

From January 2018 to March 2019, all patients attending two referral institutions with history of recurrent uncomplicated urinary stones were enrolled in this prospective phase IV, post-marketing clinical trial. All enrolled patients underwent a urological visit for inclusion and exclusion criteria assessment with quality of life (QoL) questionnaires, serum chemistry, urinalysis and non-contrast-enhanced CT scanner. All patients were encouraged to make lifestyle changes and received a food supplement containing Phyllanthus niruri and Chrysanthellum americanum in association with potassium and magnesium citrates, one capsule a day for 6 months. After 3 months, all patients were contacted by phone by the trialists in order to check the adherence to the treatment. After 6 months, all patients underwent urologic visit, urinalysis, imaging (CT scan) and QoL questionnaires evaluation. Figure 1 shows the study schedule.

\section{Outcome measures}

The main outcome measures were the reduction of symptomatic episodes and improvement in questionnaire result from baseline at the end of the follow-up period. Stone dimension reduction and stone-free status at 6 months follow-up CT scan were also considered as secondary outcome measures.

\section{Inclusion and exclusion criteria}

We considered for the inclusion, all patients with CT demonstration of one or multiple renal stones up to 15 $\mathrm{mm}$. All patients with the following characteristics were excluded: serum creatinine level $>1.6 \mathrm{mg} / \mathrm{dL}$, microbio- logical demonstration of urinary tract infection, noncontrolled diabetes, chronic liver disease and all the other serious comorbidities. Moreover, all patients with the evidence of ureterohydronephrosis or renal colic were excluded. Pregnant women were excluded, too.

Patients' clinical, laboratory and instrumental assessment At the baseline, all patients underwent urological visit with QoL questionnaires, serum chemistry and blood analysis, urinalysis and non-contrast-enhanced CT scan. The identified calculi were classified according to their number, location (superior, middle, inferior calyx) and size. Clinical data comprised systolic and diastolic blood pressure and anthropometric evaluation (weight, height, body mass index (BMI). Serum chemistry and blood analysis comprised blood count, assessment of urea, creatinine, sodium, potassium, glucose, uric acid, total and ionized calcium, total cholesterol and fractions, triglycerides, alanine aminotransferase, aspartate aminotransferase, gamma-glutamyl transpeptidase, amylase and bilirubin levels. Urinalysis with urinary $\mathrm{pH}$ measurement and a urine culture were performed using spontaneous voided urine. Moreover, before enrolment all patients received a screening evaluation which includes a medical and dietary history by an experienced nephrologist.

The enrolment has been done on the basis of the baseline metabolic profile, as suggested by the international guidelines (5).

\section{Questionnaires}

The impact of symptomatic episodes of renal stones on patients' QoL has been evaluated by using an Italian version of the Quality of Well-Being, a validated, multiattribute health scale (9). This scale was selected because

Figure 1.

\begin{tabular}{|c|c|c|c|c|}
\hline $\begin{array}{c}\text { T0 } \\
\text { Clinical, instrumental } \\
\text { laboratory } \\
\text { evaluation, Qol } \\
\text { and } \\
\text { ENROLMENT }\end{array}$ & $\begin{array}{c}\text { Food supplement } \\
1 \text { tablet every } 24 \text { hours } \\
\text { (Phyllanthus niruri, } \\
\text { Chrysanhellum } \\
\text { americanum, } \mathrm{K}^{+} \\
\text {and } \mathrm{Mg}^{+} \text {citrates) }\end{array}$ & $\begin{array}{l}\text { Treatment: } \\
6 \text { months }\end{array}$ & $\begin{array}{l}\text { V1 (3 months) } \\
\text { Contact phone for } \\
\text { evaluating adherence } \\
\text { to the treatment }\end{array}$ & $\begin{array}{l}\text { V2 (6 months) } \\
\text { Clinical, instrumental } \\
\text { laboratory } \\
\text { evaluation, Qol }\end{array}$ \\
\hline \multicolumn{5}{|c|}{ Screening (up to 3 months) } \\
\hline \multicolumn{5}{|c|}{ CONSORT FLOW DIAGRAM } \\
\hline $\begin{array}{l}\text { Assessed for } \\
\text { elegibility } \\
\quad(n=96)\end{array}$ & $\begin{array}{l}\text { Allocated to } \\
\text { intervention } \\
(n=82)\end{array}$ & & $\begin{array}{l}\text { Follow.up } \\
(n=82)\end{array}$ & $\begin{array}{l}\text { Analysed } \\
(\mathrm{n}=82)\end{array}$ \\
\hline $\begin{array}{l}\text { Excluded }(n=14) \\
\cdot \text { Not meeting inclusio } \\
\cdot \text { Declined to partecip }\end{array}$ & $(n=10)$ & & $\begin{array}{l}\text { Lost to follow-up } \\
(n=0)\end{array}$ & \\
\hline
\end{tabular}


it has been successfully applied to acute illnesses, whereas other quality of life scales, including the Short Form36 (SF-36) Health Survey, are more suitable in chronic cases. Higher scores on the QoL scale reflect a higher quality of life (10).

\section{Follow-up and efficacy assessment}

After treatment, all patients were reassessed by urologic visit with questionnaire, serum chemistry, urine analysis and imaging, in order to evaluate the changes in number, location and size of the calculi at 3 and 6 months. At 3 months all patients underwent urinary tract sonography and at 6 months non-contrast-enhanced CT scanner. At 3 months the stone evaluation was < performed by using urinary tract sonography in order to reduce the patients' exposition to X-ray. However, the stone freerate has been calculated between the baseline and the 6 months follow-up CT scan.

\section{Compounds characteristics}

All patients were treated in line with the manufacturer's instructions (Erbozeta S.p.A., RSM - https://www.erbozeta.com). Each administration contained a combination of the following ingredients: $244 \mathrm{mg}$ potassium citrate (93 $\mathrm{mg}$ potassium and $150 \mathrm{mg}$ citrate), $735 \mathrm{mg}$ magnesium citrate (30 mg magnesium and $160 \mathrm{mg}$ citrate),

Phyllanthus (Phyllantus niruri) herb d.e. 15\% mg Tannins $220 \mathrm{mg}$, Chrysanthellum (Chrysanthellum americanum Vatke) plant d.e. $1 / 455 \mathrm{mg}$.

\section{Statistical analysis}

As null hypothesis, we consider that there is no difference in terms of number of symptomatic episodes and QoL between baseline and the end of the follow-up evaluation. In order to obtain significant results to analyze, sample size calculation was based on the following assumptions: difference in terms of QoL between baseline and followup visit: $+0.3 \pm 0.06$; $\alpha$ error level, 0.05 two-sided; statistical power, $80 \%$; anticipated effect size, Cohen's $d=$ 0.5 . The calculation yielded 72 individuals. Considering a drop-out rate of $10 \%$, the final sample size was set to 79 patients. The statistical analysis was performed as follows: continuous variables are presented as median and InterQuartile Range (IQR) and categorical variables are presented as absolute (n) and relative (\%) frequency distributions. t-test were used to compare average performance between enrolment and the follow-up evaluation, and between the periods before and after enrolment. The statistical analysis was performed using SPSS.

\section{Ethical considerations}

Due to the fact that this food supplement is already present in Italian pharmacopeia and that Phyllantus niruri has been approved for the management of patients affected by urinary stones in Italy, the study did not require approval by the local ethics committee (IRB). Nevertheless, our study was conducted in line with Good Clinical Practice guidelines and the ethical principles laid down in the latest version of the Declaration of Helsinki. Before inclusion, all participants signed the written informed consent about personal data collection and storage, in accordance with national bylaws.
All anamnestic, clinical and laboratory data containing sensitive information about patients were de-identified in order to ensure analysis of anonymous data only. The de-identification process was performed by nonmedical staff by means of dedicated software. A placebo run-in period was considered unnecessary.

\section{Results}

From January 2018 to March 2019, 82 patients (mean age $49.7 \pm 11.2$ ) completed the follow-up period and were analyzed.

\section{Baseline}

At the baseline, the average stone size was $7.8 \mathrm{~mm}$ and 23 patients showed (ABU). The most common isolated strain was Enterococcus faecalis (18/23; 78.2\%).

The median number of symptomatic episodes at baseline was 3 per year. The median number of calculi was 1 (range: 1-4). In 38 patients (46.3\%) the calculi were located in the right kidney, 36 (43.9\%) had left kidney lithiasis, while 8 patients had bilateral kidney lithiasis (9.8\%). The mean stone diameter was $7.8 \pm 1.1 \mathrm{~mm}$.

The mean Hounsfield units was 637.1 \pm 264.8 , in all enrolled patients. No difference, from the normal values, has been reported in terms of urine analysis parameters among the enrolled patients. The Table 1 shows all demographic and baseline clinical and instrumental characteristics of enrolled patients.

\section{Table 1.}

Patient clinical, instrumental and laboratory characteristics at the baseline.

\begin{tabular}{|c|c|}
\hline No. of enrolled patients & 82 \\
\hline $\begin{array}{l}\text { Median age }( \pm S D) \\
\text { Sex } \\
\text { Male } \\
\text { Female }\end{array}$ & $\begin{array}{l}49.7 \pm 11.2 \\
49(59.7) \\
33(40.3)\end{array}$ \\
\hline Body Mass Index (BMI) ( \pm SD) & $25.8 \pm 6.3$ \\
\hline $\begin{array}{l}\text { Charlson Comorbidities Index } \\
0 \\
1 \\
2\end{array}$ & $\begin{array}{c}75(11.5) \\
7(8.5)\end{array}$ \\
\hline Start of urinary lithiasis (years) (range) & $2.3 \pm 0.9$ \\
\hline Number of symptomatic episodes per year ( \pm SD) & $3 \pm 1.2$ \\
\hline $\begin{array}{l}\text { History of any endourological treatment (in the last } 6 \text { months) } \\
\text { Yes } \\
\text { № }\end{array}$ & $\begin{array}{l}12(14.6) \\
70(85.4)\end{array}$ \\
\hline Median number of stones (range) & $1(1-4)$ \\
\hline Mean stone size $( \pm$ SD) $(\mathrm{mm})$ & $7.8 \pm 1.1$ \\
\hline $\begin{array}{l}\text { Stones side } \\
\text { Right kidney } \\
\text { Left kidney } \\
\text { Bilateral }\end{array}$ & $\begin{array}{c}38(46.3) \\
36(43.9) \\
8(9.8)\end{array}$ \\
\hline Mean Hounsfield Units $( \pm$ SD) & $637.1 \pm 264.8$ \\
\hline $\begin{array}{l}\text { Stones location (calyx) } \\
\text { Superior } \\
\text { Middle } \\
\text { Inferior }\end{array}$ & $\begin{array}{l}30(36.5) \\
38(46.4) \\
14(17.1)\end{array}$ \\
\hline $\begin{array}{l}\text { Presence of asymptomatic bacteriuria } \\
\text { Yes } \\
\text { № }\end{array}$ & $\begin{array}{l}23(28.1) \\
59(71.9)\end{array}$ \\
\hline $\begin{array}{l}\text { Isolated strains } \\
\text { Enterococcus faecalis } \\
\text { Escherichia coli } \\
\text { Klebsiella spp. }\end{array}$ & $\begin{array}{c}18(78.1) \\
3(13.3) \\
2(8.6)\end{array}$ \\
\hline
\end{tabular}




\section{6 months follow-up}

Adherence to the life-style changes and treatment

At the 3 months follow up by telephone call, 50 patients reported a high adherence to the life-style changes and to the treatment. At the end of the follow-up period, the adherence to the life-style changes and to the treatment was total in 60 patients $(73.1 \%)$, while in twenty-two patients (26.8\%) some minimal missing doses have been registered. A significant improvement has been reported between the 3- and 6-months evaluations in terms of adherence to the treatment and the life-style changes.

Clinical and instrumental outcomes and QoL

Twenty-seven patients out of 82 had no evidence of stone at the non-contrast-enhanced CT scanner (32.9\%) at the end of the follow-up evaluation, reporting stone expulsion, while 50 patients showed lower stones dimension (60.9\%).

The average stones size at the end of the follow-up was $0.9 \mathrm{~mm}( \pm 0.1 \mathrm{~mm})$, with a significant reduction in comparison with the baseline $(-6.7 \mathrm{~mm} \pm 3 \mathrm{~mm})(\mathrm{p}<0.001)$. Forty-nine patients (59.7\%) did not show any symptomatic episode with an improving in QoL $(+0.4 \pm 0.1)$ $(\mathrm{p}<0.001)$ in comparison to the baseline. No difference, from the normal values, has been reported in terms of urine analysis parameters among the enrolled patients. The Table 2 shows all clinical and instrumental findings at the end of the follow-up.

\section{Asymptomatic bacteriuria}

At the end of follow-up evaluation, 3 patients reported ABU. A significant reduction of patients with $A B U$ between the baseline and the end of the follow-up evaluation (23 vs 3; $\mathrm{p}<0.001$ ) has been reported.

A significant correlation between $A B U$ reduction and stones number and dimension reduction has been reported $(r=0.83 ; p<0.001)$.

\section{Adverse effects}

No mild or severe clinically significant adverse effects have been reported.

\section{Table 2.}

Clinical, instrumental and laboratory findings at each follow-up visit (3 and 6 months after treatment).

\begin{tabular}{|c|c|c|c|}
\hline & Baseline & 3 months & 6 months \\
\hline $\begin{array}{l}\text { Adherence to life-style changes recommendations } \\
\text { Patients with a high } \\
\text { Grade of adherence }\end{array}$ & - & $50(60.9)$ & 60 (73.1) \\
\hline $\begin{array}{l}\text { Clinical improvement } \\
\text { Recurrence-free patients } \\
\text { QoL } \\
\text { QoL improvement } \\
\text { Difference from baseline } \\
\end{array}$ & $\begin{array}{c}0(0 \%) \\
97.1\end{array}$ & $\begin{array}{c}38(46.3) \\
97.7 \\
+0.3 \pm 0.2 \\
p<0.001 \\
\end{array}$ & $\begin{array}{c}49(59.7) \\
97.9 \\
+0.4 \pm 0.1 \\
p<0.001 \\
\end{array}$ \\
\hline Stone-free status & $0(0 \%)$ & $19(23.1)$ & $23(32.9)$ \\
\hline $\begin{array}{l}\text { Stone size }(\mathrm{mm}) \\
\text { Stone size }(\mathrm{mm}) \\
\text { Stone size reduction } \\
\text { Difference from baseline }\end{array}$ & $7.8 \pm 1.1$ & $\begin{array}{l}3.1 \pm 0.5 \\
-4.2 \pm 2 \\
p<0.001\end{array}$ & $\begin{array}{l}1.1 \pm 0.5 \\
-6.7 \pm 3 \\
p<0.001 \\
\end{array}$ \\
\hline $\begin{array}{l}\text { Asymptomatic bacteriuria } \\
\text { Patients with asymptomatic } \\
\text { Bacteriuria } \\
\text { Difference from baseline }\end{array}$ & 23 & $\begin{array}{c}9(10.9) \\
p<0.001\end{array}$ & $\begin{array}{c}3(3.6) \\
p<0.001\end{array}$ \\
\hline
\end{tabular}

\section{Discussion}

We demonstrated that a food supplement containing Phyllanthus niruri and Chrysanthellum americanum in association with potassium and magnesium citrates is able to improve QoL in patients with urinary stones, reducing symptomatic episodes, stones number and dimension and the prevalence of asymptomatic bacteriuria. Two important points should be discussed: The role of phytotherapy in the management of urinary stones and its mechanism of action and the relationship between urinary stones and $\mathrm{ABU}$.

\section{Role of phytotherapy in the management of urinary stones and mechanism of action}

Phytotherapy is one of the first choices regarding pharmaceutical treatment of patients affected by urinary stones $(2)$ due to the demonstrated efficacy $(4,11)$ and due to the patient's preference for phytotherapeutic compounds. Micali and Pucci, in two clinical trials, demonstrated that Phyllanthus niruri is able to reduce the stone size and improve the stone free status rate $(4,11)$. In line with these trials, we found a significant reduction in terms of stones size in comparison with the baseline $(-6.7 \mathrm{~mm} \pm 3 \mathrm{~mm})(\mathrm{p}<0.001)$ and a high percentage of stone free patients after treatment.

These interesting findings are probably due to Phyllanthus niruri and Chrysanthellum americanum combination in association with potassium and magnesium citrates.

The efficacy of Phyllanthus niruri is probably augmented by the presence of Chrysanthellum americanum.

The role of Chrysanthellum americanum in the management of urinary stones is due to its interference, through the chrysantellin, a saponin, with some stages of crystallization in urine, such as a reduction in the nucleation, growth and aggregation of calcium oxalate crystals (8). Moreover, the synergistic effect of Phyllanthus niruri and Chrysanthellum americanum is probably due to its diuretic effects $(12,13)$. Furthermore, this food supplement contains potassium and magnesium citrates, although previous studies did not favor potassium citrate therapy. However, potassium can moderate the concentration of sodium in urine and promote the elevation of citrate, which acts to correct urinary $\mathrm{pH}$ and acidity, possibly contributing to an increase in calcium solubility and, then, interfere with some stages of crystallization in urine (14-17). This food supplement is, then, able to act into two different pathways: diuresis increasing and inhibition of nucleation, growth and aggregation of calcium oxalate crystals. Moving to the role of life-style changes, we found a significant improvement between the 3-and 6-months evaluations in terms of adherence to the treatment and life-style changes. The clinical reported efficacy in terms of reduction of symptomatic episodes, due to the treatment, drives the adherence to the life-style changes. In this sense, this food supplement should be considered, also, as an interesting tool for driving the adherence to the life-style changes and for obtaining a long-term efficacy on the stone recurrence. The high adherence to the treatment is due to the absence of reported adverse effects, too.

\section{Relationship between urinary stones and asymptomatic bacteriuria}

This was the first study that analyzed the efficacy of a 
food supplement in reducing ABU in patients affected by urinary stones. $\mathrm{ABU}$ is a common clinical condition among recurrent stones patients, which does not generally require any treatment. However, the role of $A B U$ in patients with recurrent urinary stones is not completely understood. Here, we demonstrated that this food supplement is able to statistically significantly reduce the prevalence of $\mathrm{ABU}$ among recurrent stone patients.

The efficacy on $\mathrm{ABU}$ is probably due to the increase of total daily diuresis and to the inhibition of nucleation, growth and aggregation of bacterial biofilm on the surface of calcium oxalate crystals. This mechanism is probably due to the Phyllanthus niruri and Chrysanthellum americanum action.

Finally, the role of bacteria biofilm on the urinary stone aggregation is another important field to deeply explore. Future studies are, however, needed to confirm these hypotheses.

\section{Conclusions}

In conclusion, this food supplement containing Phyllanthus niruri and Chrysanthellum americanum in association with potassium and magnesium citrates is able to reduce symptomatic episodes, improving QoL in patients with urinary stones and reduce the prevalence of $\mathrm{ABU}$.

\section{ACKNOWLEDGEMENTS}

The authors thank all Medical and Nursing staff at the Department of Urology, Santa Chiara Regional Hospital for clinical assistance and support of this study.

\section{References}

1. Khan SR, Pearle MS, Robertson WG, et al. Kidney stones. Nat Rev Dis Primers. 2016; 2:16008.

2. Cealan A, Coman RT, Simon V, et al. Evaluation of the efficacy of Phyllanthus niruri standardized extract combined with magnesium and vitamin $B 6$ for the treatment of patients with uncomplicated nephrolithiasis. Med Pharm Rep. 2019; 92:153-157.

3. Curhan GC, Willett WC, Knight EL, Stampfer MJ. Dietary factors and the risk of incident kidney stones in younger women: Nurses' Health Study II. Arch Intern Med. 2004; 164:885-91.

4. Pucci ND, Marchini GS, Mazzucchi E, et al. Effect of phyllanthus niruri on metabolic parameters of patients with kidney stone: a perspective for disease prevention. Int Braz J Urol. 2018; 44:758-764.

5. Prezioso D1, Strazzullo P, Lotti T, et al. Dietary treatment of urinary risk factors for renal stone formation. A review of CLU Working Group. Arch Ital Urol Androl. 2015; 87:105-20.

6. Cruces IL, Patelli THC, Tashima CM, Mello-Peixoto ECT. Plantas medicinais no controle da urolitíase. Rev Bras Pl Med. 2013; 15(4 Supl 1):780-8.

7. Ettinger B, Pak CY, Citron JT, et al. Potassium-magnesium citrate is an effective prophylaxis against recurrent calcium oxalate nephrolithiasis. J Urol. 1997; 158:2069-73.

8. Becchi M, Bruneteau M, Trouilloud M, et al. Structure of a new saponin: chrysantellin A from Chrysanthellum procumbens Rich. Eur J Biochem. 1979; 102:11-20.
9. Kaplan RM, Bush JW, Berry CC. Health status: types of validity and the index of wellbeing. Health Serv. Res. 1976; 11:478-507.

10. Apolone G, Mosconi P. The Italian SF-36 Health Survey: translation, validation and norming. J Clin. Epidemiol. 1998; 51:1025-36.

11. Micali S, Sighinolfi MC, Celia A, et al. Can Phyllanthus niruri affect the efficacy of extracorporeal shock wave lithotripsy for renal stones? A randomized, prospective, long-term study. J Urol. 2006; 176:1020-1022.

12. Nishiura JL, Campos AH, Boim MA, et al. Phyllanthus niruri normalizes elevated urinary calcium levels in calcium stone forming (CSF) patients. Urol Res. 2004; 32:362-6.

13. Udupa AL, Sanjeeva, Benegal A, et al. Diuretic activity of Phyllanthus niruri (Linn) in rats. J Health. 2010; 2:511-2.

14. Lojanapiwat B, Tanthanuch M, Pripathanont C, et al. Alkaline citrate reduces stone recurrence and regrowth after shockwave lithotripsy and percutaneous nephrolithotomy. Int Braz J Urol. 2011; 37:611-616.

15. Soygüur T, Akbay A, Küupeli S. Effect of potassium citrate therapy on stone recurrence and residual fragments after shockwave lithotripsy in lower caliceal calcium oxalate urolithiasis: a randomized controlled trial. J Endourol. 2002; 16:149-152.

16. Cicerello E, Ciaccia M, Cova G, Mangano M. The impact of potassium citrate therapy in the natural course of Medullary Sponge Kidney with associated nephrolithiasis. Arch Ital Urol Androl. 2019; 91:

17. Monti E, Trinchieri A, Magri V, et al. Herbal medicines for urinary stone treatment. A systematic review. Arch Ital Urol Androl. 2016; 88:38-46.

\author{
Correspondence \\ Tommaso Cai, MD (Corresponding Author) \\ ktommy@libero.it \\ Daniele Tiscione, MD \\ Marco Puglisi, MD \\ Gianni Malossini, MD \\ Department of Urology, Santa Chiara Hospital, Trento \\ Largo Medaglie d'Oro 9, Trento (Italy) \\ Lorenzo Ruggera, MD \\ Department of Urology, University of Padua, Padua, Italy. \\ Paolo Verze, MD \\ Department of Medicine, Surgery, Dentistry "Scuola Medica Salernitana" - \\ University of Salerno, Baronissi, Italy \\ Alessandro Palmieri, MD \\ Department of Urology, University of Naples, Federico II, Naples (Italy) \\ Davide Arcaniolo, MD \\ Department of Urology, University Vanvitelli, Naples (Italy)
}

